\title{
Optimized Planar Elliptical Dipole Antenna for UWB EMC Applications
}

\author{
Emmanouil N. Tziris, Student Member, IEEE, Pavlos I. Lazaridis, Senior Member, IEEE, Zaharias D. Zaharis, \\ Senior Member, IEEE, John P. Cosmas, Senior Member, IEEE, Keyur K. Mistry, Student Member, IEEE, and \\ Ian A. Glover, Member, IEEE
}

\begin{abstract}
This paper presents a novel method for optimizing a planar elliptical dipole antenna with elliptical slots, for ultrawideband EMC applications. The antenna is required to achieve minimum return loss and boresight realized gain with an adequate gain flatness across the frequency range of $1 \mathrm{GHz}$ to $5 \mathrm{GHz}$. Such an antenna is a powerful tool for electromagnetic measurements, due to its very compact size and its wide operating bandwidth. The main optimization method used in this study is the Invasive Weed optimization (IWO), which is a nature inspired metaheuristic evolutionary algorithm. The conventional and a modified version of IWO are compared to other prior-art evolutionary algorithms, such as the Particle Swarm Optimization and Differential Evolution. The comparison is performed by applying all the methods on a set of mathematical test functions and also on the specific antenna design problem presented in this paper. The comparative results demonstrate the superiority of the modified IWO over the other optimization methods.
\end{abstract}

Index Terms-Differential evolution, invasive weed optimization, particle swarm optimization, planar elliptical dipole, ultra-wide band antennas

\section{INTRODUCTION}

$\mathrm{T}$ HE technological advancements of the last decades in wireless communications and in new emerging technologies, such as the Internet of Things, have brought to the surface a wide range of devices. It is expected that wireless communications will grow more rapidly than ever before. Such expectations indicate that the research on Electromagnetic Compatibility (EMC) becomes more and more necessary.

According to Federal Communications Commission's (FCC) regulation, ultra-wideband (UWB) radio technology refers to technology that has an absolute bandwidth greater than 500 $\mathrm{MHz}$ or a fractional bandwidth greater than 0.2 . Fig. 1 depicts a typical UWB spectrum. This differs from narrowband technologies, where the fractional bandwidth is typically less than 0.1 .

Manuscript received December 15, 2018

This paper is for the Special Issue and is an expanded version from the 2018 IEEE Symposia in Singapore and Long Beach.

E. N. Tziris and J. P. Cosmas are with Brunel University, London, Uxbridge, UB8 3PH, United Kingdom (e-mail: emmanouil.tziris@brunel.ac.uk; john.cosmas@brunel.ac.uk).

P. I. Lazaridis, K. K. Mistry, and I. A. Glover are with the Department of Engineering and Technology, University of Huddersfield, Huddersfield HD1 3DH, United Kingdom (e-mail: p.lazaridis@hud.ac.uk; keyur.mistry@hud.ac.uk; i.a.glover@hud.ac.uk).

Z. D. Zaharis is with the Department of Electrical and Computer Engineering, Aristotle University of Thessaloniki, Thessaloniki 54124, Greece (e-mail: zaharis@auth.gr).
Many types of UWB antennas have been proposed and studied so far. Some of the most basic types of UWB antennas are the biconical antenna, the discone antenna and the logperiodic dipole array (LPDA). Also, the planar monopole antennas, which are fabricated on PCB, demonstrate satisfactory radiation characteristics for bandwidths up to $10 \mathrm{GHz}$. The planar elliptical dipole has been proposed among other structures as an antenna with good broadband radiation characteristics. Unlike the traditional broadband dipole elements that must be approximately equal to a half wavelength in length to radiate efficiently, a planar elliptical dipole still exhibits a return loss less than $-10 \mathrm{~dB}$ for an element size of $0.20 \lambda$ and an efficiency of $50 \%$ for an element size of $0.14 \lambda$ [1][5]. All these translate to a compact antenna with large bandwidth and adequate efficiency.

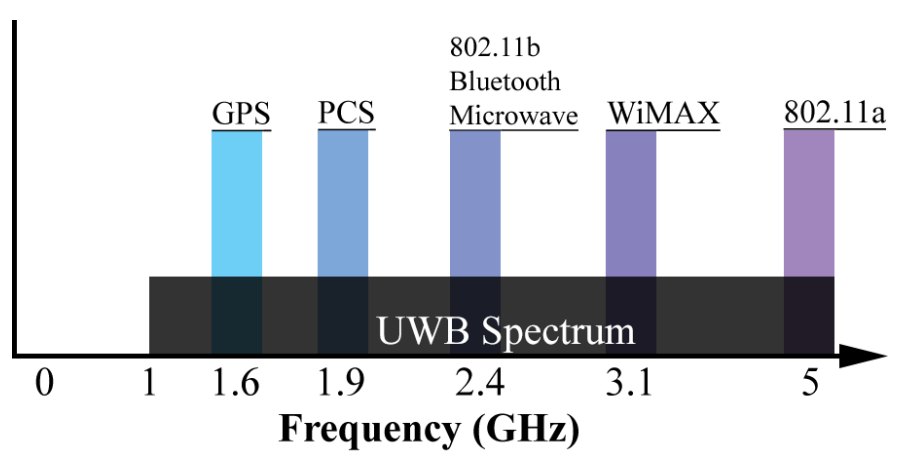

Fig. 1. 1-5 GHz spectrum displaying some of the most popular technologies and their corresponding frequencies within that spectrum.

Several studies have been carried out on various types of planar elliptical dipole antennas presenting their wideband capabilities. They have radiation characteristics very similar to that of a biconical antenna, and yet they are much less expensive in fabrication [6]-[11]. Efforts have been made to improve the performance of such antennas and to simplify their design. In some studies, bottom fed structures have been developed to avoid baluns and elliptical slots have been added to widen the operating bandwidth [12]-[16].

In this study, an effort is made to improve even further the performance of such an antenna by using 3D electromagnetic simulation. CST EM 3D simulation together with some of the most powerful Evolutionary Algorithms (EAs) have been used and have been proven to be very effective computational tools for electromagnetic applications [17], [18]. The algorithms employed for optimization in the present study are the 
conventional and a modified version of the Invasive Weed Optimization (IWO) algorithm, the inertia weight version of the Particle Swarm Optimization (PSO) algorithm, and a Differential Evolution (DE) algorithm based on the popular $\mathrm{DE} / \mathrm{rand} / 1$ strategy. All the algorithms have been coded in MATLAB and are used here to optimize the geometry parameters of the antenna, while the radiation characteristics of the optimized antenna geometries derived by the respective algorithms are compared. The ultimate aim of this study is to generate an antenna, which is characterized by compact size, low cost, operation over an ultra-wide frequency range and finally by sufficiently high realized gain as well as sufficiently low gain flatness over this frequency range. It is noted that gain flatness is the maximum variation of the realized gain over a frequency range. Such an antenna that combines all these features is preferable for UWB EMC measurements.

\section{EVOLUTIONARY AlgORITHMS}

EAs are powerful tools, which are utilized in many scientific fields, primarily for the purposes of optimization and design. As previous research indicates, EAs have been proven to be very effective for optimizing the geometry of antenna structures for specific applications [17], [18]. EAs are heuristic-based approaches for solving problems and, in most cases, yield nearglobal optimum results for a predetermined multi-target problem. In general, the phases of execution of an EA are: (1) Initialization of a population of particles. The size of the population is determined by the size of the search space (i.e., the number of parameters to be optimized), (2) Fitness Evaluation, where the fitness of each individual in a certain population is calculated, (3) Evolution, where individuals are evolved according to a certain mechanism in order to improve their fitness and thus become members of the next population, and (4) Termination, where the process comes to an end by recording the positions of the individuals in the search space together with their fitness values, and is then repeated from the second phase until a fixed amount of iterations is reached.

Below, we give a brief description of four important EAs, which are going to be compared between each other.

\section{A. Inertia Weight Particle Swarm Optimization}

The PSO, as stated by its developers, has roots to both genetic algorithms and evolutionary strategies [19]. It is similar to genetic algorithms in that the initialization consists of a random population of possible solutions called particles, yet it differs because each particle is assigned with a random velocity, which defines the movement of the particle towards the best solution.

Particle swarms have been studied in two types of neighborhoods, called global best (g-best) and local best (1best). In the g-best neighborhood, every particle is attracted to the best position found by the whole swarm. This position is called "g-best position". Due to its nature, the g-best model suffers from a tendency to get stuck in near optimum solutions. For this reason, many studies have been carried out to improve its accuracy by employing mixed methodologies [20], [21]. In the l-best neighborhood, each individual is affected by the best performance of its immediate neighbors and it is attracted to the best position found by these neighbors. This position is called "l-best position". The l-best neighborhood is considered to be more effective and thus it is employed in this study [22], [23].

According to the 1-best model, the velocity $\overrightarrow{\mathrm{u}}_{\mathrm{i}}$ of the $\mathrm{i}$-th particle after a time step is given by

$$
\begin{aligned}
\overrightarrow{\mathrm{u}}_{\mathrm{i}}(\mathrm{t}+1)=w \overrightarrow{\mathrm{u}}_{\mathrm{i}}(\mathrm{t}) & +\mathrm{c}_{1} \operatorname{rand}(\mathrm{t})\left[\overrightarrow{\mathrm{p}}_{\mathrm{i}}(\mathrm{t})-\overrightarrow{\mathrm{x}}_{\mathrm{i}}(\mathrm{t})\right] \\
& +\mathrm{c}_{2} \operatorname{rand}(\mathrm{t})\left[\overrightarrow{\mathrm{l}}_{\mathrm{i}}(\mathrm{t})-\overrightarrow{\mathrm{x}}_{\mathrm{i}}(\mathrm{t})\right]
\end{aligned}
$$

where $\mathrm{w}$ is the inertia weight, $\mathrm{c}_{1}$ and $\mathrm{c}_{2}$ are factors called "cognitive coefficient" and "social coefficient" respectively, $\vec{l}_{\mathrm{i}}$ is the 1-best position found by the neighborhood of the i-th particle, $\vec{x}_{i}$ and $\vec{p}_{i}$ are respectively the current position of the i-th particle and the best position found by this particle until time step $t$, and lastly, $\operatorname{rand}(\mathrm{t})$ is a function that generates random numbers uniformly distributed between 0 and 1 . Due to the use of inertia weight in (1), the above version of PSO is called inertia weight PSO (IWPSO).

\section{B. Differential Evolution}

$\mathrm{DE}$ is a global optimization method for many real-valued problems and is a very simple, yet exceptionally powerful method. DE is a floating-point encoding evolutionary algorithm for global optimization over continuous spaces but can also work with discrete variables. It creates new candidate solutions by combining the parent individual and several other individuals of the same population. A candidate replaces the parent only if it has better fitness value. Nonetheless, DE requires preliminary work by the user, such as control parameter tuning, which is a difficult task. Self-adaptation of control parameters is an important feature for DE, because it serves as a very practical solution to the control parameter tuning problem by configuring itself accordingly.

Some of the most popular strategies applied in DE are $\mathrm{DE} / \mathrm{rand} / 1, \mathrm{DE} / \mathrm{rand} / 2, \mathrm{DE} /$ best $/ 1$ and DE/best/2. Prior-art has shown that $\mathrm{DE} / \mathrm{rand} / 1$ and $\mathrm{DE} / \mathrm{rand} / 2$ are the most effective strategies [24], and in this paper the $\mathrm{DE} / \mathrm{rand} / 1$ strategy is employed. According to this strategy, after the initialization phase, for each i-th particle, DE creates a vector calculated as $\overrightarrow{\mathrm{V}}_{\mathrm{i}, \mathrm{n}}=\overrightarrow{\mathrm{X}}_{1, \mathrm{n}}+\mathrm{F}\left(\overrightarrow{\mathrm{X}}_{2, \mathrm{n}}-\overrightarrow{\mathrm{X}}_{3, \mathrm{n}}\right)$

where $\vec{X}_{1, \mathrm{n}}, \vec{X}_{2, \mathrm{n}}$ and $\vec{X}_{3, \mathrm{n}}$ are the position vectors of three randomly chosen particles, $\mathrm{F}$ is a positive real number called mutation scaling factor and used to scale the vector difference, and finally $\mathrm{n}$ is the current iteration.

\section{Conventional Invasive Weed Optimization}

The IWO method, originally proposed by Mehrabian and Lucas in 2006 [25], simulates the colonizing behavior of weeds in nature. This behavior is simulated by the following phases:

(1) Initialization of positions (i.e., random dispersion) of a finite number of weeds across a given search space.

(2) Reproduction of every grown weed (plant) into new seeds depending on its own fitness value and according to the following linear formula:

$X_{s}=\operatorname{int}\left(\frac{F_{w}-F_{s}}{F_{w}-F_{b}}\right) X_{\text {MAX }}$ 
where $X_{s}$ is the number of seeds produced by the s-th weed, $\mathrm{X}_{\max }$ is the maximum number of seeds produced by a weed, $\mathrm{F}_{\mathrm{w}}$ and $F_{b}$ are respectively the worst (maximum) and the best (minimum) fitness value of the population, and finally $F_{s}$ is the fitness value of the s-th weed. In (3), it is considered that the worst weed is not permitted to produce any seeds at all $\left(X_{\mathrm{w}}=0\right)$.

(3) Spatial dispersion of the newly produced seeds according to a Gaussian distribution with standard deviation expressed as:

$\mathrm{SD}=\left(\frac{\mathrm{I}_{\mathrm{MAX}}-\mathrm{I}}{\mathrm{I}_{\mathrm{MAX}}}\right)^{\mathrm{n}}\left(\mathrm{SD}_{\mathrm{in}}-\mathrm{SD}_{\mathrm{fi}}\right)+\mathrm{SD}_{\mathrm{fi}}$

where I and $\mathrm{I}_{\mathrm{MAX}}$ are respectively the current and the maximum number of iterations, $\mathrm{SD}_{\mathrm{in}}$ and $\mathrm{SD}_{\mathrm{fi}}$ are respectively defined as the initial and final standard deviation, and $\mathrm{n}$ is the nonlinear modulation index used to define the reduction rate of SD.

(4) Competitive exclusion, where all the weeds are sorted according to their fitness values and then weeds with high fitness are eliminated until a predefined number of them is left. The above process is repeated from the 2 nd phase until a predefined number of iterations $\mathrm{I}_{\mathrm{MAX}}$ is completed. It has been shown that IWO is a very effective optimization method for electromagnetic applications [25]-[29].

\section{Modified Invasive Weed Optimization}

In this paper, a modified form of (3) is proposed, where a nonlinear seed production index $a$ is introduced as shown below:

$$
X_{s}=\operatorname{int}\left[\left(\frac{F_{w}-F_{s}}{F_{w}-F_{b}}\right)^{\alpha}\right] X_{\text {MAX }}
$$

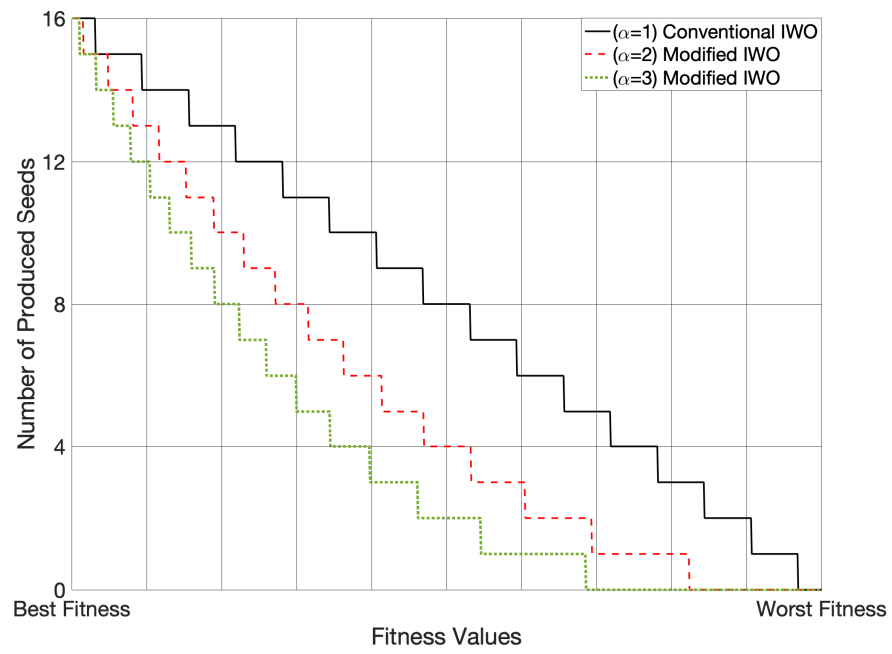

Fig. 2. Number of produced seeds per weed versus the fitness value of the weed for various values of index $\alpha$.

If $a=1$, the seed production is linear and then (5) is identical to (3), which means that the modified IWO turns into its conventional version. Fig. 2 displays the number of produced seeds versus the weed fitness for three different values of $a$, i.e., 1,2 and 3. By starting with $a=1$ (linear production case) and increasing, the seed production is reduced for all the weeds, but in percentage this reduction is higher for the bad weeds (with high fitness values), while the good weeds do not undergo any significant decrease in seed production. Therefore, an increase in the value of $a$ is an easy way to benefit from the exploration ability of the good weeds without delaying the optimization process due to the limited exploration ability of the bad weeds.

However, the value of $a$ cannot be increased indefinitely. Large values of $a$ make the algorithm unable to exploit weeds with quite good fitness values, because a large $a$ forces even quite good weeds undergo a significant decrease in seed production (see modified IWO with $a=3$ in Fig. 2). Then, the optimization process may get stuck on a local optimum solution, which indeed corresponds to a good fitness but not to the best one. By properly adjusting the value of $a$, the modified IWO achieves better performance than the conventional IWO.

To find the optimal value of $a$, the IWO algorithm is tested on 10 different test functions with several different values of $a$. A PSO and a DE algorithm participate in this comparison. All the algorithms employ populations of 20 particles and are applied to every test function using 30 dimensions (i.e., 30 variables), except two test functions which are defined in a 2D space due to their nature. Each optimization algorithm is executed 500 times per test function with 20000 fitness evaluations per execution and the final fitness value is recorded per execution and per test function. Every set of 500 final fitness values per test function and per algorithm is used to calculate the statistical mean final fitness (Mean Fit) and the respective standard deviation (Std Dev). These statistical results are summarized in Table I. It is obvious that the modified IWO algorithm with $a=2$ outperforms all the other algorithms.

TABLE I

Mean Value and Standard DeViation of The Final Fitness Values

\begin{tabular}{|c|c|c|c|c|c|}
\hline $\begin{array}{c}\text { Test } \\
\text { Function }\end{array}$ & $\begin{array}{c}\text { IWO } \\
(\alpha=1) \\
\text { Mean Fit } \\
\text { /Std Dev } \\
\end{array}$ & $\begin{array}{c}\text { IWO } \\
(\alpha=2) \\
\text { Mean Fit } \\
\text { /Std Dev } \\
\end{array}$ & $\begin{array}{c}\text { IWO } \\
(\alpha=3) \\
\text { Mean Fit } \\
\text { /Std Dev }\end{array}$ & $\begin{array}{c}\text { PSO } \\
\text { Mean Fit } \\
\text { /Std Dev }\end{array}$ & $\begin{array}{c}\text { DE } \\
\text { Mean Fit } \\
\text { /Std Dev }\end{array}$ \\
\hline Ackley's & $\begin{array}{c}0.19 \\
/ \mathbf{0 . 2 9}\end{array}$ & $\begin{array}{c}\mathbf{0 . 1 3} \\
/ 0.33\end{array}$ & $\begin{array}{l}0.17 \\
/ 0.43\end{array}$ & $\begin{array}{l}2.67 \\
/ 1.12\end{array}$ & $\begin{array}{l}6.44 \\
/ 1.90\end{array}$ \\
\hline $\begin{array}{l}\text { De Jong's } \\
\text { N.1 }\end{array}$ & $\begin{array}{l}0.00 \\
/ 0.00\end{array}$ & $\begin{array}{l}0.00 \\
/ 0.00\end{array}$ & $\begin{array}{l}0.00 \\
/ 0.00\end{array}$ & $\begin{array}{l}0.00 \\
/ 0.00\end{array}$ & $\begin{array}{l}0.23 \\
/ 0.51\end{array}$ \\
\hline $\begin{array}{c}\text { De Jong's } \\
\text { N.3 }\end{array}$ & $\begin{array}{l}0.03 \\
/ 0.01\end{array}$ & $\begin{array}{c}0.01 \\
/ 0.00\end{array}$ & $\begin{array}{l}0.01 \\
/ 0.00\end{array}$ & $\begin{array}{l}0.02 \\
/ 0.07\end{array}$ & $\begin{array}{l}0.09 \\
/ 0.21\end{array}$ \\
\hline $\begin{array}{l}\text { De Jong's } \\
\text { N.4 }\end{array}$ & $\begin{array}{l}\mathbf{0 . 0 0} \\
/ \mathbf{0 . 0 0}\end{array}$ & $\begin{array}{l}0.00 \\
/ 0.00\end{array}$ & $\begin{array}{l}0.00 \\
/ 0.00\end{array}$ & $\begin{array}{l}0.00 \\
/ 0.00\end{array}$ & $\begin{array}{l}0.08 \\
/ 0.18\end{array}$ \\
\hline Easom (2D) & $\begin{array}{l}-1.00 \\
/ 0.00\end{array}$ & $\begin{array}{r}-1.00 \\
/ 0.00\end{array}$ & $\begin{array}{l}-1.00 \\
/ 0.00\end{array}$ & $\begin{array}{r}-1.00 \\
/ 0.00\end{array}$ & $\begin{array}{l}-1.00 \\
/ 0.00\end{array}$ \\
\hline $\begin{array}{c}\text { Holder } \\
\text { Table (2D) }\end{array}$ & $\begin{array}{c}-19.21 \\
/ 0.00\end{array}$ & $\begin{array}{c}-19.21 \\
/ 0.00\end{array}$ & $\begin{array}{c}-19.21 \\
/ 0.00\end{array}$ & $\begin{array}{c}-19.14 \\
/ 0.80\end{array}$ & $\begin{array}{c}-19.20 \\
/ 0.10\end{array}$ \\
\hline Michalewicz & $\begin{array}{c}-22.12 \\
/ 1.37\end{array}$ & $\begin{array}{l}-21.24 \\
/ 1.47\end{array}$ & $\begin{array}{l}-20.71 \\
/ 1.59\end{array}$ & $\begin{array}{c}-25.21 \\
/ 1.31\end{array}$ & $\begin{array}{l}-21.15 \\
/ 3.17\end{array}$ \\
\hline Rastrigin & $\begin{array}{l}56.43 \\
/ 12.42\end{array}$ & $\begin{array}{l}65.27 \\
/ 15.21\end{array}$ & $\begin{array}{l}71.77 \\
/ 17.46\end{array}$ & $\begin{array}{c}57.42 \\
/ 15.19\end{array}$ & $\begin{array}{c}34.40 \\
/ 10.46\end{array}$ \\
\hline Rosenbrock & $\begin{array}{l}47.81 \\
/ 45.25\end{array}$ & $\begin{array}{c}44.44 \\
/ 38.56\end{array}$ & $\begin{array}{l}47.41 \\
/ 40.27\end{array}$ & $\begin{array}{l}45.65 \\
/ 35.71\end{array}$ & $\begin{array}{c}1269.80 \\
/ 3926.80\end{array}$ \\
\hline Schwefel & $\begin{array}{c}-287.57 \\
/ 19.36\end{array}$ & $\begin{array}{c}-278.65 \\
/ 20.29\end{array}$ & $\begin{array}{l}-271.15 \\
/ 20.41\end{array}$ & $\begin{array}{c}-229.94 \\
/ 28.41\end{array}$ & $\begin{array}{c}-311.62 \\
/ 19.69\end{array}$ \\
\hline
\end{tabular}




\section{RESULTS}

The geometry of a planar elliptical dipole antenna with elliptical slots is defined by eight parameters in total. These are: (1) the outer length, (2) the outer width, (3) the inner length of the slots, (4) the inner width of the slots, (5) the feeding gap between the two ellipses, (6) the offset between the inner and outer ellipses, (7) the substrate length, and (8) the substrate width. All these parameters are shown in Fig. 3. The antenna feeding is applied between its two elliptical segments and is modeled in CST by a discrete face port, that has a characteristic impedance of $50 \Omega$. The dielectric substrate used in the simulations is chosen to be Rogers RT/duroid 5880LZ, which is suitable for microstrip circuit applications and is thus used for the fabrication of the antenna. The characteristics of the substrate are its relative permittivity $\varepsilon_{\mathrm{r}}$, which is equal to 2 , and its thickness, which is equal to $2.54 \mathrm{~mm}(0.1 \mathrm{inch})$, while the copper thickness is $0.035 \mathrm{~mm}$. These three characteristics have fixed values and thus are not under optimization.

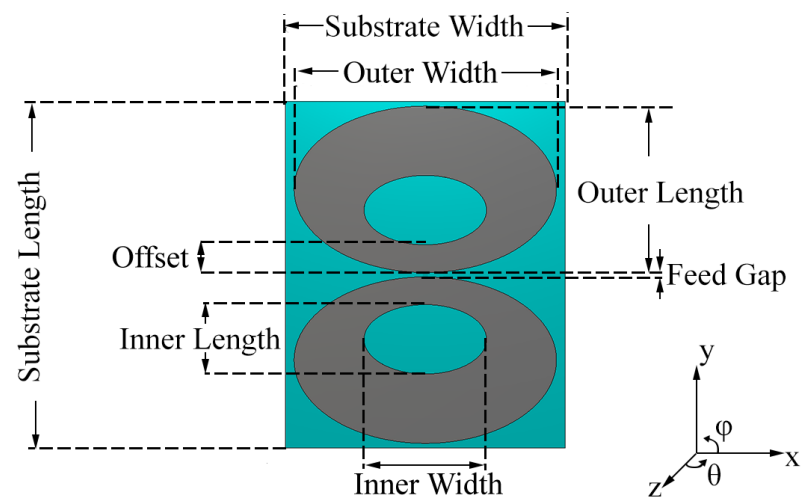

Fig. 3. Geometrical parameters of a planar elliptical dipole antenna.

The desired operating frequency range is defined from $1 \mathrm{GHz}$ to $5 \mathrm{GHz}$. This range is almost in the same region with the operating frequency range of a similar antenna given in [16]. Therefore, we can choose initial values for the above parameters equal to those given in [16] and consider that the optimum values will not deviate more than $30 \%$ from the initial ones. In this way, we can define a lower and an upper boundary for each geometry parameter. However, there is an exception from the above consideration that concerns the ellipse offset and the feeding gap. These two parameters are very crucial for the antenna behavior. Therefore, we decided to extend their value range from $1 \mathrm{~mm}$ to twice their respective initial value in order to help the optimization algorithms find proper values for these two parameters. All the initial values and the respective boundaries are summarized in Table II.

The optimization goal is to further improve the antenna performance over the range $1-5 \mathrm{GHz}$ by finding the best possible combination of values of the geometry parameters. The performance of the antenna over the above range is characterized by the $S_{11}$ parameter (i.e., the return loss), the boresight (i.e., at $\theta=0$ as shown in Fig. 3) realized gain (RG) and the gain flatness (GF). The requirements defined for these characteristics over the entire band are as follows:

(1) $\mathrm{S}_{11} \leq-10 \mathrm{~dB},(2) \mathrm{RG} \geq 2 \mathrm{dBi}$, and (3) $\mathrm{GF} \leq 2 \mathrm{~dB}$.
TABLE II

INITIAL VALUES AND BOUNDARIES OF ANTENNA GEOMETRY PARAMETERS

\begin{tabular}{cccc}
\hline \hline Parameter & $\begin{array}{c}\text { Initial } \\
\text { Value } \\
(\mathbf{m m})\end{array}$ & $\begin{array}{c}\text { Lower } \\
\text { Boundary } \\
(\mathbf{m m})\end{array}$ & $\begin{array}{c}\text { Upper } \\
\text { Boundary } \\
(\mathbf{m m})\end{array}$ \\
\hline Substrate Length & 106.00 & 74.20 & 137.80 \\
Substrate Width & 85.00 & 59.50 & 110.50 \\
Ellipse Outer Length & 38.00 & 26.60 & 49.40 \\
Ellipse Outer Width & 79.00 & 55.30 & 102.70 \\
Ellipse Inner Length & 19.50 & 13.65 & 25.35 \\
Ellipse Inner Width & 37.50 & 26.25 & 48.75 \\
Ellipse Offset & 3.50 & 1.00 & 7.00 \\
Feeding Gap & 1.50 & 1.00 & 3.00 \\
\hline \hline
\end{tabular}

A fitness function is set for the antenna optimization and is expressed as a linear combination of three terms, which are respectively defined according to the three previously mentioned requirements. Each term is multiplied by a respective weight $\left(\mathrm{w}_{1}, \mathrm{w}_{2}\right.$ and $\left.\mathrm{w}_{3}\right)$. The weights are used to determine the importance of every term and therefore the risk of satisfying only one of the three requirements against the rest is diminished. In this study, the weights of the terms that concern $\mathrm{S}_{11}$ and $\mathrm{RG}$ are set to be equal, since the respective two requirements are considered of equal importance. The weight of the term that concerns GF is equal to a quarter of the previous weights, due to the fact that the respective requirement is of lower importance. The terms are respectively described as follows:

$\mathrm{T}_{1}=\max \left(\mathrm{S}_{11, \max }, \mathrm{S}_{11, \text { desired }}\right)-\mathrm{S}_{11, \text { desired }}$,

$\mathrm{T}_{2}=\mathrm{RG}_{\text {desired }}-\min \left(\mathrm{RG}_{\min }, \mathrm{RG}_{\text {desired }}\right)$,

and

$\mathrm{T}_{3}=\max \left(\mathrm{GF}_{\text {actual }}, \mathrm{GF}_{\text {desired }}\right)-\mathrm{GF}_{\text {desired }}$,

where $\mathrm{S}_{11 \text {,desired }}=-10 \mathrm{~dB}, \mathrm{RG}_{\text {desired }}=2 \mathrm{dBi}, \mathrm{GF}_{\text {desired }}=2 \mathrm{~dB}$, $\mathrm{S}_{11 \text {, max }}$ and $\mathrm{RG}_{\min }$ are respectively the maximum $\mathrm{S}_{11}$ and the minimum $\mathrm{RG}$ found over the entire band, and finally $\mathrm{GF}_{\text {actual }}=\mathrm{RG}_{\text {max }}-\mathrm{RG}_{\min }\left(\mathrm{RG}_{\max }\right.$ is the maximum $\mathrm{RG}$ found over the entire band). Due to the above definitions, the fitness function is described by the following formula:

Fit $=\mathrm{w}_{1} \mathrm{~T}_{1}+\mathrm{w}_{2} \mathrm{~T}_{2}+\mathrm{w}_{3} \mathrm{~T}_{3}$,

where $\mathrm{w}_{1}=\mathrm{w}_{2}=4$ and $\mathrm{w}_{3}=1$. From (9), it is obvious that Fit has positive values and vanishes only when all three requirements are satisfied.

The algorithms employed to optimize the antenna geometry are DE, PSO, Conventional IWO, Modified IWO with $\alpha=2$ and Modified IWO with $\alpha=3$. By taking into account the complexity of the optimization process (where CST simulations are involved when fitness calculations are demanded by the optimization algorithms), we decided to use populations of 15 particles for all the algorithms. Every algorithm is executed five times in total and the best result of each algorithm is presented in this paper. Each execution stops after 2500 evaluations, which is considered sufficient to achieve the minimum possible fitness value. The simulations were carried out on a workstation that uses an Intel i7-7820X CPU operating at $4 \mathrm{GHz}$, along with $16 \mathrm{~GB}$ of RAM and no GPU acceleration. The average computation time per fitness evaluation was approximately 30 seconds using the CST time domain solver. It should be noted 
that the computation time is heavily affected by the total number of the antenna CST model's mesh cells, which are approximately 50,000. Also, magnetic symmetry in the yzplane and electric symmetry in the xz-plane is considered for the antenna CST model. Fig. 4 depicts the best fitness convergence graph achieved by every algorithm. It is obvious that the modified IWO algorithm with $a=2$ again outperforms all the other algorithms. Table III shows the optimized values of the antenna geometry parameters derived from the modified IWO with $\alpha=2$, PSO and DE, while Table IV shows the respective antenna characteristics. From Fig. 4, it is obvious that the results derived from the conventional IWO and the modified IWO with $\alpha=3$ are much worse than those derived from the modified IWO with $\alpha=2$. Therefore, we decided not to include in Tables III and IV the results from the conventional IWO and the modified IWO with $\alpha=3$.

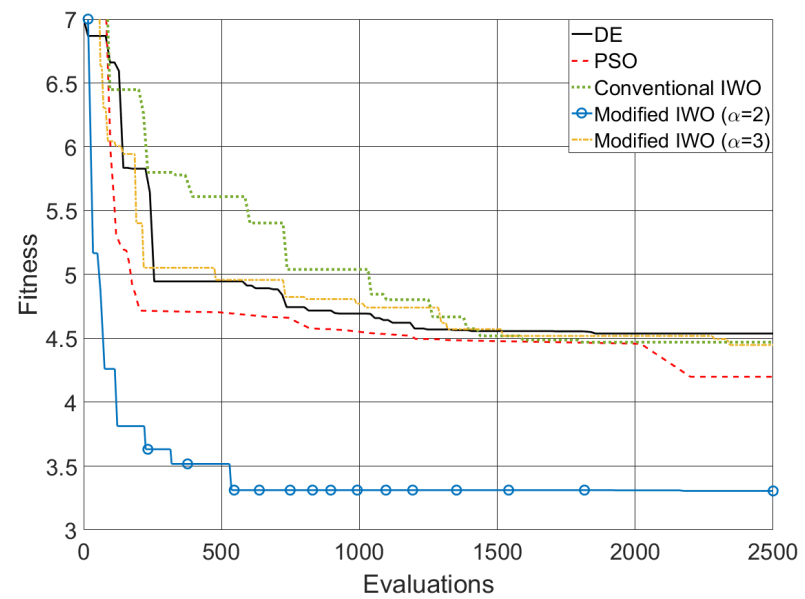

Fig. 4. Best fitness convergence graphs achieved by DE, PSO, conventional IWO, modified IWO with $\alpha=2$ and modified IWO with $\alpha=3$, for the optimization of a planar elliptical dipole antenna.

TABLE III

OPTIMIZED VALUES OF ANTENNA GEOMETRY PARAMETERS

\begin{tabular}{|c|c|c|c|}
\hline Parameter & $\begin{array}{c}\text { Modified } \\
\text { IWO }(\alpha=2)\end{array}$ & PSO & DE \\
\hline Substrate Length $(\mathrm{mm})$ & 116.92 & 112.74 & 103.97 \\
\hline Substrate Width (mm) & 99.09 & 90.44 & 85.42 \\
\hline Ellipse Outer Length (mm) & 48.56 & 48.59 & 48.6 \\
\hline Ellipse Outer Width (mm) & 77.71 & 78.25 & 79.77 \\
\hline Ellipse Inner Length (mm) & 21.74 & 20.08 & 20.27 \\
\hline Ellipse Inner Width (mm) & 30.38 & 37.85 & 39.55 \\
\hline Ellipse Offset (mm) & 5.23 & 6.47 & 5.86 \\
\hline Feeding Gap (mm) & 1.42 & 1.31 & 1.00 \\
\hline
\end{tabular}

TABLE IV

DESIRED AND OPTIMIZED VALUES OF ANTENNA CHARACTERISTICS

\begin{tabular}{lcccc}
\hline \hline $\begin{array}{c}\text { Antenna } \\
\text { Characteristics }\end{array}$ & $\begin{array}{c}\text { Desired } \\
\text { Values }\end{array}$ & $\begin{array}{c}\text { Modified } \\
\text { IWO }(\boldsymbol{\alpha}=\mathbf{2})\end{array}$ & PSO & DE \\
\hline $\mathrm{S}_{11, \max }(\mathrm{dB})$ & -10.00 & -11.12 & -9.99 & -9.95 \\
$\mathrm{RG}_{\min }(\mathrm{dBi})$ & 2.00 & 1.62 & 1.75 & 1.77 \\
$\mathrm{GF}(\mathrm{dB})$ & 2.00 & 2.9 & 3.46 & 3.61 \\
\hline \hline
\end{tabular}

The antenna geometry extracted from the modified IWO with $\alpha=2$ was fabricated and experimentally measured in terms of $\mathrm{S}_{11}$. The comparative results of $\mathrm{S}_{11}$ are given in Fig. 5, while comparative results of RG are shown in Fig. 6. The fabricated antenna is shown in Fig. 7.

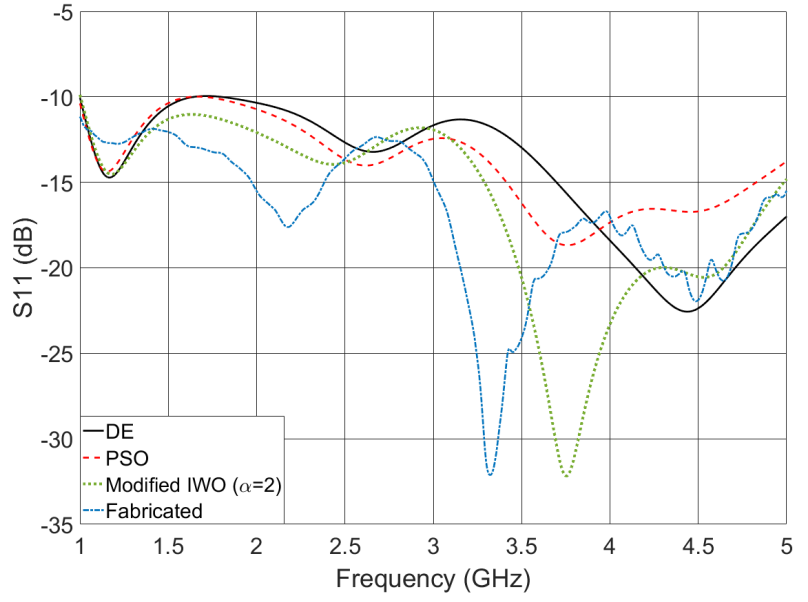

Fig. 5. $\mathrm{S}_{11}$ of the planar elliptical dipole antenna optimized by DE, PSO and modified IWO with $\alpha=2$, and $S_{11}$ of the fabricated antenna according to the modified IWO based geometry.

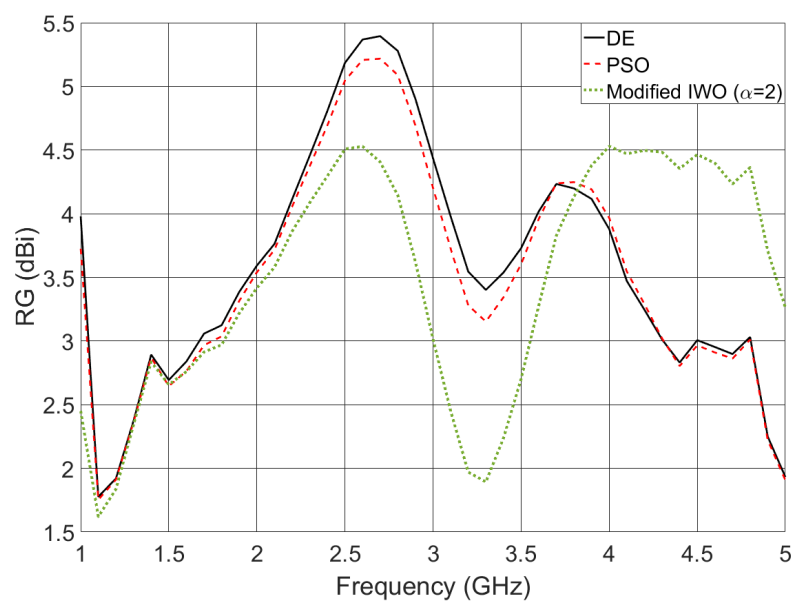

Fig. 6. RG of the planar elliptical dipole antenna optimized by DE, PSO and modified IWO with $\alpha=2$.

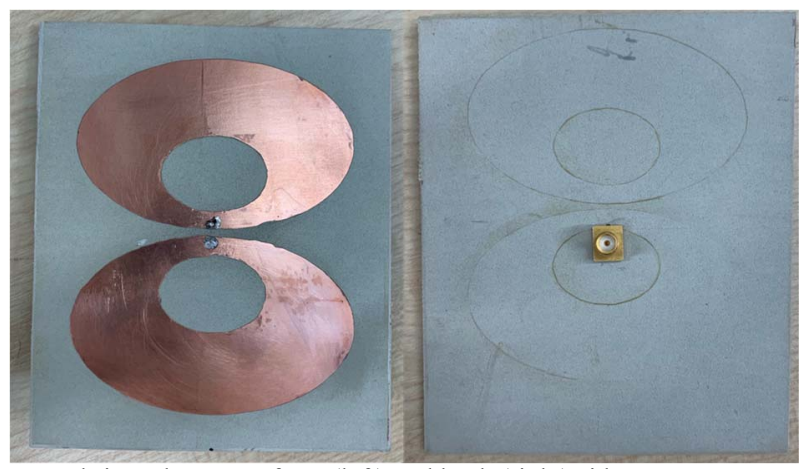

Fig. 7. Fabricated antenna front (left) and back (right) side.

A general comment extracted from Figs. 4-6 and Table IV is that all the algorithms are able to produce antenna geometries with characteristics very close to their respective desired values. From Fig. 5, it seems that all of the evolutionary algorithms achieve values of $S_{11}$ below the desired one over the entire frequency range. Also, Fig. 6 presents some interesting results because, despite the fact that all the algorithms come close to the optimization goals, the modified IWO (with $\alpha=2$ ) exhibits a better GF over the entire band, while DE and PSO yield much higher RG values for the biggest part of the frequency range. 


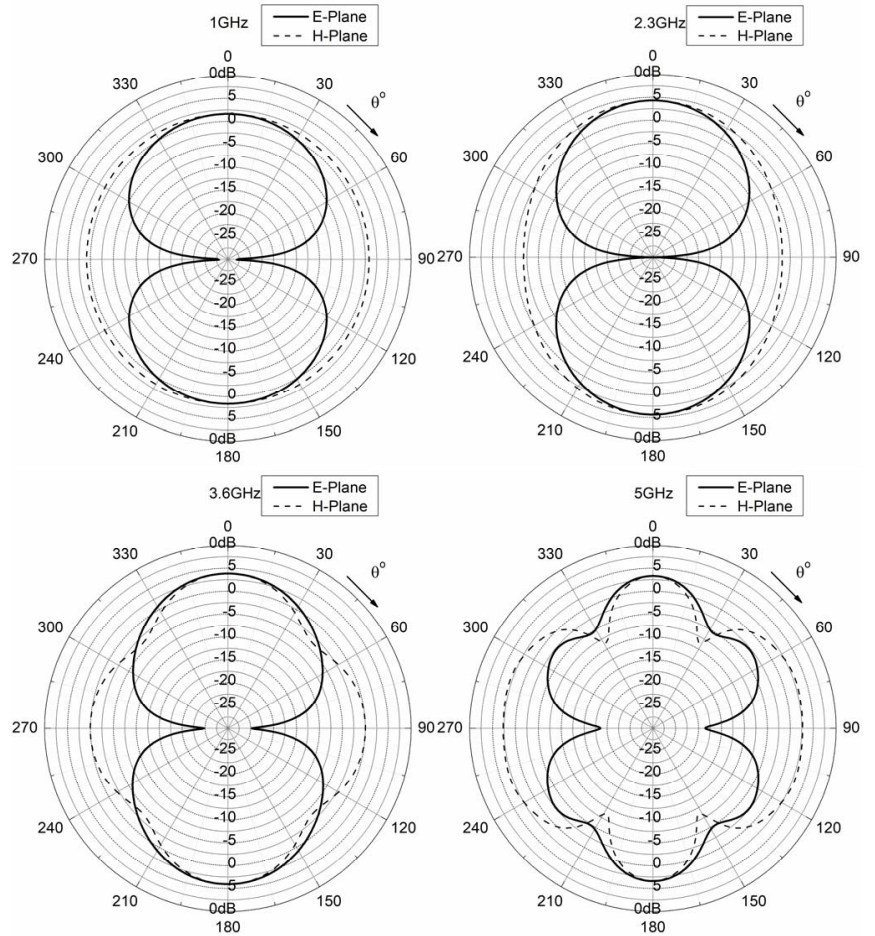

Fig. 8. Radiation pattern of the modified IWO based (with $\alpha=2$ ) planar elliptical dipole antenna for $1 \mathrm{GHz}, 2.3 \mathrm{GHz}, 3.6 \mathrm{GHz}$ and $5 \mathrm{GHz}$.

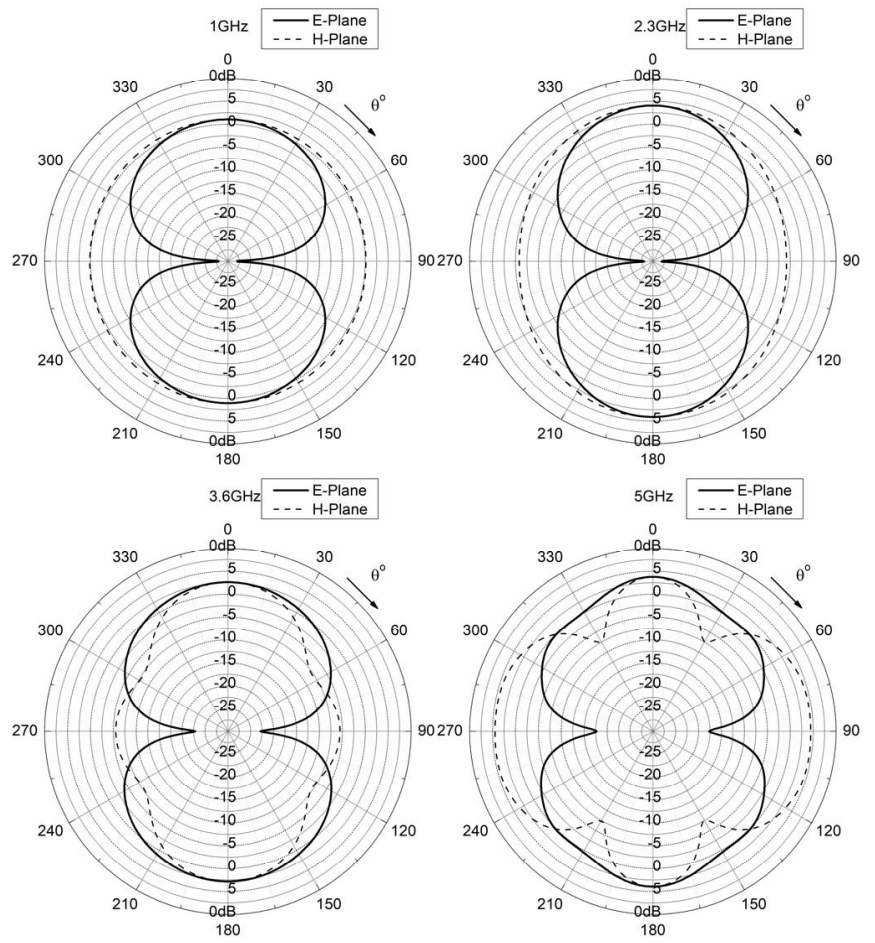

Fig. 9. Radiation pattern of the PSO based planar elliptical dipole antenna for $1 \mathrm{GHz}, 2.3 \mathrm{GHz}, 3.6 \mathrm{GHz}$ and $5 \mathrm{GHz}$.

Figs. 8-10 display the radiation patterns of the optimized antenna geometries in four frequencies, i.e., 1, 2.3, 3.6 and 5 GHz. In the region 1-3 GHz, the antenna is almost omnidirectional in the H-plane and produces two symmetrical lobes in the E-plane. At frequencies above $3 \mathrm{GHz}$, side lobes begin to appear in the H-plane and this also happens in the E- plane at frequencies above $5 \mathrm{GHz}$, resulting thus in a gradual reduction of the boresight $\mathrm{RG}$.

The antenna optimized in this paper is a lightweight, compact and low-cost structure, it has easy fabrication and demonstrates unique radiation characteristics as previously shown. Therefore, the antenna could be a promising tool for EMC applications, such as UWB radiation measurements and spectrum surveillance.

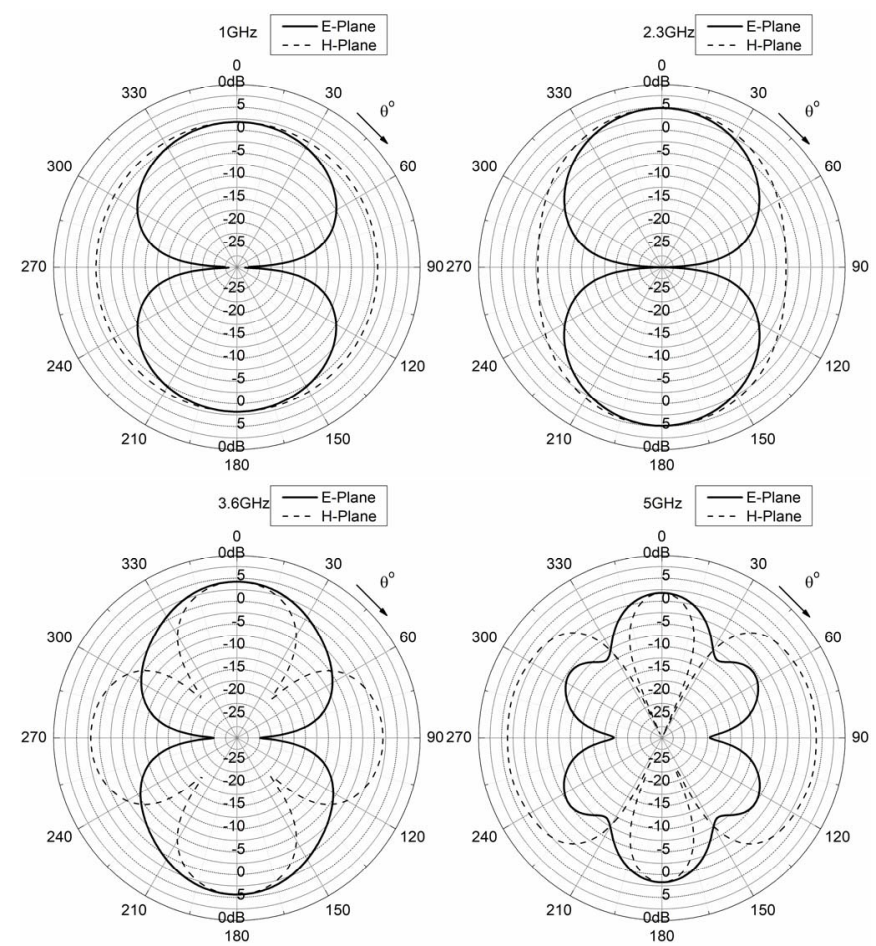

Fig. 10. Radiation pattern of the DE based planar elliptical dipole antenna for $1 \mathrm{GHz}, 2.3 \mathrm{GHz}, 3.6 \mathrm{GHz}$ and $5 \mathrm{GHz}$

\section{CONCLUSION}

The geometry parameters of an improved planar elliptical dipole antenna with elliptical slots have been optimized under specific requirements for $S_{11}, R G$ and $G F$ over an ultra-wide band $1-5 \mathrm{GHz}$, by using four different evolutionary algorithms, namely the conventional IWO, a modified version of IWO, the inertia weight version of PSO and a DE algorithm based on the $\mathrm{DE} / \mathrm{rand} / 1$ strategy. The above algorithms have been coded in MATLAB and the antenna has been modeled in CST Microwave studio. The time domain solver of CST software has been used because it is better suited to broadband analysis. The optimized antenna geometries derived by the above algorithms seem to adequately satisfy all the requirements over the major part of the frequency band. Furthermore, the modified IWO seems to be a very effective optimization method and deserves to be studied in more detail in the future.

\section{REFERENCES}

[1] G. Kevanishvili, Z. Sikmashvili, I. Kevanishvili, K. Kotetishvili, A. Asanidze, and G. Chikhladze, "About the electromagnetic compatibility of dipole antenna," in Proc. 13th International Seminar/Workshop on Direct and Inverse Problems of Electromagnetic and Acoustic Wave Theory, Tbilisi, 2008, pp. 73-76. 
[2] F. Lin, Y. Qi, J. Fan, and Y. Jiao, "0.7-20-GHz dual-polarized bilateral tapered slot antenna for EMC measurements," IEEE Trans. Electromagn. Compat., vol. 56, no. 6, pp. 1271-1275, 2014.

[3] Q. Wu, X. Ding, and D. Su, "A compact dipole antenna with curved reflector for 1.0-4.2 GHz EMC measurement," IEEE Trans. Electromagn. Compat., vol. 57, no. 6, pp. 1289-1297, 2015.

[4] M. Aram, H. Tahmasbi, and H. Aliakbarian, "An ultra-wideband miniaturized printed dipole antenna for EMC measurements," in Proc. International Symposium on Electromagnetic Compatibility - EMC EUROPE, 2017, pp. 1-4.

[5] E. Tziris, J. Cosmas, Z. Zaharis, T. Xenos, P. Lazaridis, K. Mistry, and I. Glover, "Invasive weed optimized planar elliptical dipole antenna for ultra-wideband EMC applications," in Proc. IEEE International Symposium on Electromagnetic Compatibility and IEEE Asia-Pacific Symposium on Electromagnetic Compatibility (EMC/APEMC), Singapore, 2018, pp. 233-236.

[6] H. Schantz, "Planar elliptical element ultra-wideband dipole antennas," in Proc. IEEE Antennas and Propagation Society International Symposium (IEEE Cat. No.02CH37313), San Antonio, TX, USA, 2002.

[7] P. Cerny and M. Mazanek, "Optimized ultra wideband dipole antenna," in Proc. 18th International Conference on Applied Electromagnetics and Communications, Dubrovnik, Croatia, 2005, pp. 1-4.

[8] H. Schantz, W. Beeler, and D. Dickson, "UWB planar bulbous dipole antennas," in Proc. IEEE Antennas and Propagation Society International Symposium, Washington, DC, 2005, vol. 2A, pp. 475-478.

[9] J. Zhang, Y. Xu, and W. Wang, "Ultra-wideband microstrip-fed planar elliptical dipole antenna," Electronics Letters, vol. 42, no. 3, p. 144, 2006.

[10] J. Yu, M. Zhou, Y. Yao, L. Guo, X. Chen, S. Liu, Y. Cen, and Y. Gao, "Study of an ultra wideband planar elliptical dipole antenna," in Proc. International Conference on Microwave Technology and Computational Electromagnetics (ICMTCE 2009), Beijing, China, 2009, pp. 49-52.

[11] W. Toh, X. Qing, and Z. Chen, "A planar UWB patch-dipole antenna," IEEE Trans. Antennas Propag., vol. 59, no. 9, pp. 3441-3444, 2011.

[12] J. Powell and A. Chandrakasan, "Differential and single ended elliptical antennas for 3.1-10.6 GHz ultra wideband communication," in Proc. IEEE Antennas and Propagation Society Symposium, Monterey, CA, USA, 2004, pp. 2935-2938.

[13] C. Lee, C. Wang, R. Yen, and H. Huang, "Broadband printed-circuit elliptical dipole antenna covering $750 \mathrm{MHz}-6.0 \mathrm{GHz}$," in Proc. International Conference on Microwave and Millimeter Wave Technology, Nanjing, 2008, pp. 1207-1209.

[14] B. Tian, C. Feng, and M. Deng, "Planar miniature elliptical monopole antenna for ultra wideband radios," in Proc. International Conference on Microwave and Millimeter Wave Technology, Nanjing, China, 2008, pp. 1240-1242.

[15] G. Whyte, F. Darbari, I. McGregor, I. Glover, and I. Thayne, "Different feeding geometries for planar elliptical UWB dipoles, and the excitation of leakage current," in Proc. 38th European Microwave Conference, Amsterdam, Netherlands, 2008, pp. 1382-1385.

[16] H. Nazli, E. Bicak, B. Turetken, and M. Sezgin, "An improved design of planar elliptical dipole antenna for UWB applications," IEEE Antennas and Wireless Propagation Letters, vol. 9, pp. 264-267, 2010.
[17] P. Lazaridis, E. Tziris, Z. Zaharis, T. Xenos, J. Cosmas, P. Gallion, V. Holmes, and I. Glover, "Comparison of evolutionary algorithms for LPDA antenna optimization," Radio Science, vol. 51, no. 8, pp. 13771384, Aug. 2016.

[18] P.Lazaridis, E. Tziris, Z. Zaharis, T. Xenos, V. Holmes, J. Cosmas, and I. Glover, "Comparative study of broadcasting antenna array optimization using evolutionary algorithms," in Proc. URSI Asia-Pacific Radio Science Conference (URSI AP-RASC), Seoul, 2016, pp. 1299-1301.

[19] R. Eberhart and J. Kennedy, "A new optimizer using particle swarm theory," in Proc. 6th International Symposium on Micro Machine and Human Science, Nagoya, Japan, 1995, pp. 39-43

[20] S. Jun and L. Jian, "A hybrid of differential evolution and particle swarm optimization for global optimization," in Proc. 3rd International Symposium on Intelligent Information Technology Application, Shanghai, 2009, pp. 138-141.

[21] W. Lin, Z. Lian, X. Gu, and B. Jiao, "A local and global search combined particle swarm optimization algorithm and its convergence analysis," Mathematical Problems in Engineering, vol. 2014, Article ID 905712, 2014

[22] Z. Zaharis, D. Kampitaki, A. Papastergiou, A. Hatzigaidas, P. Lazaridis, and M. Spasos, "Optimal design of a linear antenna array under the restriction of uniform excitation distribution using a particle swarm optimization based method," WSEAS Transactions on Communications, vol. 6, no. 1, pp. 52-59, 2007.

[23] Z. Zaharis, D. Kampitaki, P. Lazaridis, A. Papastergiou, and P. Gallion, “ On the design of multifrequency dividers suitable for GSM/DCS/PCS/UMTS applications by using a particle swarm optimization-based technique," Microwave and Optical Technology Letters, vol. 49, no. 9, pp. 2138-2144, 2007.

[24] Y. Ao and H. Chi, "Experimental study on differential evolution strategies," in Proc. WRI Global Congress on Intelligent Systems, Xiamen, 2009, pp. 19-24.

[25] A. Mehrabian and C. Lucas, "A novel numerical optimization algorithm inspired from weed colonization," Ecological Informatics, vol. 1, no. 4, pp. 355-366, 2006.

[26] A. Mallahzadeh, H. Oraizi, and Z. Davoodi-Rad, "Application of the invasive weed optimization technique for antenna configurations," Progress In Electromagnetics Research, vol. 79, pp. 137-150, 2008.

[27] S. Karimkashi and A. A. Kishk, "Invasive weed optimization and its features in electromagnetics," IEEE Trans. Antennas Propag., vol.58, no.4, pp.1269-1278, Apr. 2010.

[28] Z. Zaharis, C. Skeberis, T. Xenos, P. Lazaridis, and D. Stratakis, "IWObased synthesis of log-periodic dipole array," in Proc. International Conference on Telecommunications and Multimedia (TEMU), Crete, Greece, 2014, pp. 150-154.

[29] P. Lazaridis, Z. Zaharis, C. Skeberis, T. Xenos, E. Tziris, and P. Gallion, "Optimal design of UHF TV band log-periodic antenna using invasive weed optimization," in Proc. 4th International Conference on Wireless Communications, Vehicular Technology, Information Theory and Aerospace \& Electronic Systems (VITAE), Aalborg, Denmark, 2014, pp. $1-5$. 